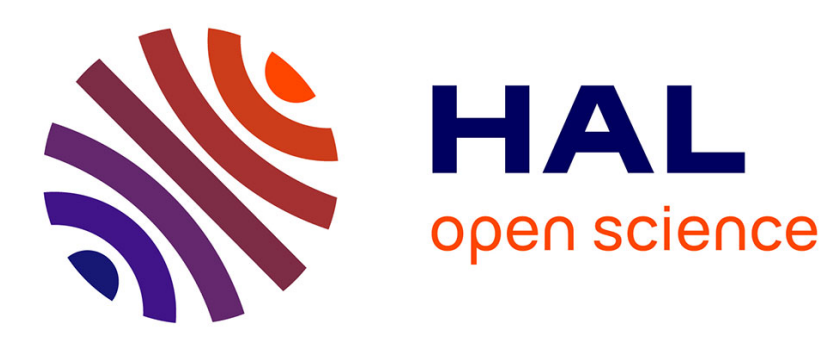

\title{
The effectiveness of dietary therapy over 10 years in the treatment of Adult Refsum Disease
}

Eleanor J Baldwin, F Brian Gibberd, Claire Harley, Margaret C Sidey, Michael D Feher, Anthony S Wierzbicki

\section{- To cite this version:}

Eleanor J Baldwin, F Brian Gibberd, Claire Harley, Margaret C Sidey, Michael D Feher, et al.. The effectiveness of dietary therapy over 10 years in the treatment of Adult Refsum Disease. Journal of Neurology, Neurosurgery and Psychiatry, 2010, 81 (9), pp.954. 10.1136/jnnp.2008.161059 . hal00557403

\section{HAL Id: hal-00557403 \\ https://hal.science/hal-00557403}

Submitted on 19 Jan 2011

HAL is a multi-disciplinary open access archive for the deposit and dissemination of scientific research documents, whether they are published or not. The documents may come from teaching and research institutions in France or abroad, or from public or private research centers.
L'archive ouverte pluridisciplinaire HAL, est destinée au dépôt et à la diffusion de documents scientifiques de niveau recherche, publiés ou non, émanant des établissements d'enseignement et de recherche français ou étrangers, des laboratoires publics ou privés. 


\section{The effectiveness of long-term dietary therapy in the treatment of Adult Refsum Disease}

Eleanor J. Baldwin

Research dietician

F. Brian Gibberd

Consultant

Claire Harley

Dietician

Margaret C. Sidey

Clinical Assistant

Michael D. Feher

Consultant

Anthony S. Wierzbicki

Consultant

Refsum Disease Clinic, Chelsea \& Westminster Hospital, London SW10 9NH UK

Key words: Refsum disease; phytanic acid; diet; peroxisome

$\begin{array}{lc}\text { Abstract } & 193 \text { words } \\ \text { Text Words } & 2441 \\ \text { Tables } & 2 \\ \text { Figures } & \text { Nil } \\ \text { References } & 31\end{array}$

Address for correspondence

Anthony S. Wierzbicki

Department of Chemical Pathology St Thomas'

Hospital

Lambeth Palace Road

London SE1 7EH

Tel: $\quad$ (44)-207-188-1256

Fax: (44)-207-928-4226

E-mail: $\quad$ Anthony.Wierzbicki@kcl.ac.uk 


\section{$\underline{\text { Abstract }}$}

Objective: to evaluate the long-term effectiveness of dietary therapy with regular dietetic reinforcement for Adult Refsum disease

Methods: Retrospective case note analysis of records of plasma phytanic acid and hospital admission of 13 patients with Adult Refsum Disease who attended the specialist centre and repeatedly received dietary instruction for a minimum of ten years.

Results: Patients undergoing review had attended for 11-28 years totaling 237 years. Median baseline phytanic acid concentrations at presentation were 1631 (370-2911) $\mu \mathrm{mol} / \mathrm{l}$ and declined by $89 \pm 11 \%$ to $85(10-1325) \mu \mathrm{mol} / \mathrm{l}$. Levels of phytanic acid were completely normalised $(<30 \mu \mathrm{mol} / \mathrm{L})$ in $30 \%$; partially normalised $(30-300 \mu \mathrm{mol} / \mathrm{L})$ in $50 \%$ and remained $>$ $300 \mathrm{pmol} / \mathrm{L}$ in $15 \%$. The time required for phytanic acid levels to halve was $44.2 \pm 15.9$ months in patients compliant with diet. No patient required admission or plasmapheresis/apheresis during this period for acute neuro-ophthalmological complications despite occasional spikes in phytanic acid levels attributable to intercurrent illness, surgery, sudden weight loss or psychological illness.

Interpretation: Dietary modification with regular reinforcement in Adult Refsum Disease can significantly reduce phytanic acid levels with time. 


\section{Introduction}

Adult Refsum Disease (ARD; OMIM 266500) is a rare autosomal recessive disorder of peroxisomal metabolism[1 2234 . The biochemical abnormality in ARD is a substantially reduced ability to metabolise the alpha-methyl isoprenoid fatty acid $-3 R, S, 7 R, 11 R, 15-$ tetramethylhexadecanoic acid also known as phytanic acid (PA). The average intake of PA on a western diet is estimated to be 50-100mg per day[5]. Slow accumulation of PA occurs in neuronal and adipose tissue in patients with ARD from the peri-natal period and may lead to neuroophthalmological presentation with night blindness and allied retinitis pigmentosa with anosmia in teenage years. Alternatively, if these symptoms are not noticed, PA continues to accumulate and patients present about 10 years later with symptoms including acute weakness, ataxia, sensory neuropathy, cardiomyopathy and ichthyosis. This acute presentation is usually secondary to an infection or other intercurrent illness. Phytanic acid is metabolised by alpha-oxidation with a secondary pathway of omega-oxidation[6]. Mutations affecting enzymes or transporters in the alpha-oxidation pathway including phytanoyl-coA hydroxylase $(\mathrm{PhyH})$ or its peroxisomal import protein peroxin 7 are responsible for most cases of ARD[7]. In patients with ARD plasma levels are probably determined by the balance of intake, residual alpha-oxidation, omega-oxidation and renal excretion.[8]. This study describes the long-term efficacy of a diet-focused strategy on plasma PA levels.

\section{$\underline{\text { Methods }}$}

A retrospective case note audit was conducted using a standard form. Ethical consent was not considered to be required for an anonymous audit survey by the institutional ethics review board. Inclusion criteria comprised a confirmed diagnosis of ARD including identifications of mutations 
in the relevant genes (phytanoyl-coA hydroxylase (PhyH); peroxin 7 (Pex7) or $\alpha$-methyl-acyl cholesteryl racemase (AMACR); attendance at the Refsum Clinic for 10 years or more; UK residence and current attendance. Exclusion criteria were absence of inclusion factors for inclusion in the study. The audit of each patient commenced at their first point of contact with the Refsum disease clinic, or if their first contact had occurred when admitted acutely unwell, after initial management, including plasmapheresis had taken place. Most patients with ARD attend and have attended the clinic at least every 6 months. Management at each visit consists of clinical and dietetic review, and counseling on the Westminster Refsum diet[9 10]. At each visit weight and plasma phytanic acid are measured and patients are questioned about adherence to the diet, any intercurrent illnesses, hospital admissions or procedures since the previous visit. The dietetic review is conducted over 30 minutes and includes review of recent diet including detailed assessment of food groups consumed, advice on use of specific supplements (Fresubin) and answering of any questions raised by the patient.

For this study information on body weight, PA level, symptoms of ARD and other relevant details (e.g. intercurrent illness) was extracted from the case notes and recorded on standardised audit forms by the auditors working in parallel in pairs. Phytanic acid was measured by the same gas chromatographic method for the whole period of follow-up. Clinical admission data was obtained from patient records, including those to outside centres, and categorised as being due to ARD or for other medical reasons.

The clinic uses a PA concentration $>1500 \mu \mathrm{mol} / \mathrm{L}$ and presence of symptoms typical of acute ARD (weakness, sensory loss, sudden visual deterioration) as the criterion for requesting admission. No standardised definition of a biochemical exacerbation of ARD exists but any 
definition should include its severity, its frequency and the temporal course of these episodes. For the purposes of this study the investigators pre-specified that clinical and biochemical exacerbations of ARD should be diagnosed by the presence of a $>50 \%$ rise in PA from the preceding visit and exceeding a baseline $10 \mathrm{x}$ upper limit of normal (ULN) (>300 $\mu \mathrm{mol} / \mathrm{L})$. The $50 \%$ rise was derived as an approximation of the Westgard criterion (one sided change) used in clinical chemistry to show a significant deviation from mean levels (1.96 x SD)[11] using the ERNDIM data for the variances of PA assays[12]. Patients were questioned regularly about symptoms associated with ARD.

Data was analysed by construction of time series plots of PA for each patient. Given the non-normal distribution of the data median concentrations and ranges are quoted for cohort analyses. Plasma halving time (half life) of PA levels was calculated for each individual including all available data after log transformation. Good control was defined as a reduction of PA of $>50 \%$ and/or achieving a PA $<10 \times$ ULN $(<300 \mu \mathrm{mol} / \mathrm{L})$. These figures are arbitrary and based on clinical experience that patients achieving PA levels $<300 \mu \mathrm{mol} / \mathrm{L}$ show no signs of progression of ARD.

\section{Results}

Twenty five patients attend the ARD clinic on regular basis. Thirteen patients ( 8 male and 5 female) with ARD had attended the clinic for 10 years or more from 1977 to 2005 and met the inclusion criteria. All patients in this cohort had mutations in PhyH or mapped to chromosome 10. Three patients had received plasmapheresis on admission for a total of 5 exchanges over the 
period of the first week of admission. Patients were excluded for lack of extended follow-up ( $\mathrm{n}=10$; all $<5$ years follow-up) and lack of compliance with regular review having being lost to follow-up for extended intervals ( $>2$ years) $(n=2)$. Duration of follow-up was 237 patient-years with an average attendance of 17.9 \pm 4 years (range 11-28 years). Inactivating mutations in the phytanoyl-coA hydroxylase (PhyH) gene were found in $11 / 13$ patients $(87 \%)$ and the other cases have previously been mapped to chromosome 10[13]. Median baseline phytanic acid concentrations at presentation the clinic were 1631 (370-2911) $\mu \mathrm{mol} / \mathrm{l}$ and declined by a mean of $89 \pm 11 \%$ to a median $85(10-1325) \mu \mathrm{mol} / \mathrm{l}$ (table 1$)$. One patient previously had a recorded higher initial PA concentration of $5888 \mu \mathrm{mol} / \mathrm{L}$ at another hospital assayed by another method prior to plasmapheresis. In this case the local PA level on admission was used. 4 patients (31\%) achieved levels of PA in the normal range while only $2(15 \%)$ had levels after $>10$ years

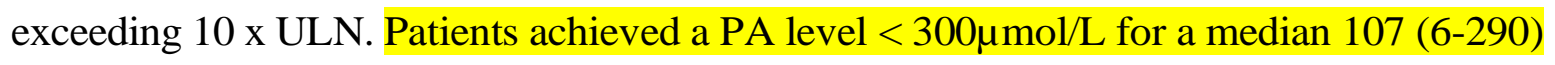
months or 48 (3-97) \% of the time. The half life for PA was 39 (20-78) months in patients $(\mathrm{n}=10)$ achieving a $>50 \%$ reduction in PA levels from baseline.

No patient required admission for acute symptoms of ARD in the cohort. All patients stated they could comply with the diet. No patient described any side-effects they attributed to the diet. The PA level declined in all patients with time. However, a number of periods of sustained increases in PA levels were seen (table 2). The commonest reasons associated with these increases were sudden weight loss, poor compliance with diet, recurrent infections while in primary care, and admission for medical or surgical reasons not related to ARD. None of these was associated by patients with acute severe irreversible deterioration in their senses of vision, hearing, smell, balance or with gait problems. 


\section{$\underline{\text { Discussion }}$}

Data on long-term follow-up of cohorts of patients treated with diet or other methods is scanty. This study of 13 patients with 237 patient years of follow-up shows that dietary therapy reduces PA levels by a mean of $89 \pm 11 \%$ (change in median levels: $1631 \mu \mathrm{mol} / \mathrm{L}$ to $85 \mu \mathrm{mol} / \mathrm{L}$ ) and that $30 \%$ of patients achieved levels of PA in the normal range while a further $55 \%$ achieved PA levels $<10 \mathrm{x}$ ULN. The mean half life of PA in patients receiving dietary therapy was 39 (20-78) months. In this cohort there were no admissions were necessary for acute stabilisation of ARD. The frequency and severity of biochemically defined PA exacerbations also fell with time in parallel with reductions in overall PA levels.

Two different strategies exist for treatment of ARD. As PA is derived from the diet and transported on lipoproteins[14] concentrations can be reduced either by physical extraction of lipoproteins using plasmapheresis or apheresis or by dietary restriction of PA intake. Initial acute management of ARD revolves around supportive management of symptoms, restriction of PA intake and removal of PA by plasmapheresis or apheresis. Clinical observations in acute ARD suggest that as PA levels fall below $1000 \mu \mathrm{mol} / \mathrm{L}$ the ataxia, peripheral neuropathy, myopathy and ichthyosis all gradually resolve[15]. Controversy exists about the long-term management of ARD with two alternative approaches being pursued. Some groups favour life time regular (fortnightly- monthly) plasma exchange allied to a low phytanic acid diet [16] while others favour the sole use of dietary modification. There is little long-term data about the efficacy of either approach except for case reports [17 18]. Plasmapheresis is efficient at removing PA associated with lipoproteins but is inefficient in depleting total body PA, as most PA is found in adipose and 
neural tissue, and these depots show slow exchange with plasma [15 1920 21]. Plasmapheresis is expensive and carries a risk of excess morbidity due to its invasive nature. There is no large scale long-term data on the effectiveness of plasmapheresis in ARD though many reports show that it is effective in the short-term [17 18 21]. In contrast to plasmapheresis, a diet low in PA and free phytol is inexpensive but has generally been thought to be limited in efficacy by poor compliance. Current dietetic management in ARD has 4 principles:-

1. avoidance of rapid weight loss or prolonged periods of fasting;

2. restriction of dietary intake of PA to $<10 \mathrm{mg} /$ day

3. avoidance of immoderate intakes of caffeine and other adrenergic stimulants (because they stimulate hepatic lipolysis and PA release);

4. institution of nutritional support, parenteral products known to contain insignificant amounts of PA during episodes of anorexia, starvation or on hospital admission for other reasons.

Case reports of symptomatic improvement and lowering of phytanic acid levels in the blood in response to short term dietary treatment have been published[20 22] but these relate to one or two patients and the sustainability of dietary modification is not addressed. One case report of long-term management with diet over 42 years exists[23]. 
In contrast this study shows that long-term dietary therapy is effective in reducing PA levels. Only a minority of patients $(n=4 ; 33 \%)$ were non-compliant as shown by persistent elevations over previous levels ( $>20 \%)$ and then only on an episodic basis $(<1$ year). However, the data presented in this report are not totally internally consistent as the dietary regime used has evolved over the last 30 years. Historically, initial dietary management on presentation (when patients were commonly acutely unwell, anorexic, with low body mass index and vomiting) consisted of nutritional support via a liquid diet based on skimmed milk powder, a glucose polymer, safflower seed oil and milk shake syrup (until the advent of commercial nutritionally complete feeds)[5 15]. Patients were subsequently weaned on to a solid diet consisting of foods known to provide $0.5 \mathrm{mg}$ of PA per 100g to a total of not more than 10mg of PA daily. Foods known to be rich in phytol were excluded (all green vegetables, many fruits and nuts)[24]. Vitamin supplementation was provided. A more detailed account of the original Westminster diet is given by Masters-Thomas in 1980[25 26]. In the 1980s the dietary treatment changed to allow green vegetables after investigation of the effects of phytol-rich foodstuffs [10]. Phytol can be oxidised to PA exists in man utilising the fatty aldehyde dehydrogenase -10 [27] (FALDH-10) pathway affected in Sjögren -Larsson syndrome (OMIM 270200); however, this source is not clinically significant [27 28 29]. The diet was further modified after more comprehensive analysis of the PA content of foods in the 1990s resulting in still fewer dietary restrictions[9].

The importance of avoiding substantial weight loss, or extended periods of fasting had been suspected clinically for many years[30]. The kinetics of this response became clear when 5 patients fasted as part of a study of omega-oxidation. In these patients PA rose acutely with a doubling time of 14 hours [8]. The clinical reports of side-effects in this audit confirms the 
importance of the avoidance of weight loss and of appropriate in-patient management (including nutritional supplementation) as $53 \%$ of acute clinical exacerbations were attributed to sudden weight loss[30]. Compliance with the ARD diet has been an issue but has become easier as the diet has been simplified. Due to the nature of the design of this study it is difficult to disentangle improved adherence due to habituation to the diet from subjective feelings of improvement as PA levels fall. Easier adherence to the diet therapy would be expected as the dietary restrictions have been progressively liberalised. The majority of patients state that they manage to stick to the current diet without difficulty yet it still remains a major source of concern that many exacerbations are caused by admitted poor adherence to diet even despite regular dietetic review.

This study is subject to a number of limitations. PA levels are a surrogate marker for outcomes and symptoms but the rarity of ARD makes endpoint studies almost impossible to conduct. Arbitrary (though clinically plausible) definitions has been made in this study for PA levels likely to precipitate admission, those that represent varieties of clinical control and a mathematical definition has been derived to identify significant changes in PA levels likely to indicate a potential clinical exacerbation. However, patients were unblinded with regard to PA results, no systematic objective disability scoring was conducted and thus the association of periods of PA deterioration in ARD-associated symptoms cannot be definitively confirmed.

\section{$\underline{\text { Conclusions }}$}

This retrospective case note analysis demonstrates that regular dietary review and education on the Westminster diet is effective in producing a sustained reduction in PA over many years. None of 
the subjects developed acute complications requiring admission or plasmapheresis during the period of study though many did show periods of significant deterioration in PA levels especially early on in treatment. Adherence to the diet was generally good though intermittent for some individuals. Regular review may be the key to achieving and maintaining a sustained reduction in PA levels, particularly during episodes of illness, and in the management of rapid weight loss.

Acknowledgments Dr Brian Gibberd established the Refsum disease clinic at Westminster Hospital and he died suddenly in 2007 after completing the basic data analysis for this paper[31]. Details of services for patients and clinician about Refsum disease are available from http://www.refsumdisease.org

\section{Licence for Publication:}

The Corresponding Author has the right to grant on behalf of all authors and does grant on behalf of all authors, an exclusive licence (or non exclusive for government employees) on a worldwide basis to the BMJ Publishing Group Ltd to permit this article (if accepted) to be published in PMJ and any other BMJPGL products and sublicences such use and exploit all subsidiary rights, as set out in our licence.

Competing Interest: None declared. 
Table 1

Clinical characteristics of patients with Refsum disease

\begin{tabular}{|c|c|c|c|c|c|c|c|}
\hline Patient & Sex & $\begin{array}{l}\text { Age at } \\
\text { presentatio } \\
\text { n (years) }\end{array}$ & $\begin{array}{l}\text { Follow- } \\
\text { up } \\
\text { (years) }\end{array}$ & Mutation & $\begin{array}{l}\text { Initial } \\
\text { PA } \\
\text { level }\end{array}$ & $\begin{array}{l}\text { Final } \\
\text { PA } \\
\text { level }\end{array}$ & $\begin{array}{l}\text { Decrea } \\
\text { se }(\%)\end{array}$ \\
\hline 1 & $\mathrm{~F}$ & 56 & 18 & $?(\operatorname{maps} 10 \mathrm{p})$ & 1540 & 10 & 99.8 \\
\hline 2 & $\mathrm{M}$ & 35 & 17 & Exon 6 splice & 467 & 80 & 59 \\
\hline 3 & $\mathrm{M}$ & 46 & 11 & Exon 3 splice & 886 & 55 & 94 \\
\hline 4 & $\mathrm{M}$ & 26 & 17 & Exon 6 splice & 362 & 85 & 77 \\
\hline 5 & $\mathrm{M}$ & 26 & 18 & $\begin{array}{l}\text { Exon } 3 \\
\text { splice Q40X }\end{array}$ & 2054 & 162 & 92 \\
\hline 6 & M & 30 & 18 & $\begin{array}{l}\text { Exon } 3 \\
\text { splice Q40X }\end{array}$ & 1129 & 213 & 81 \\
\hline 7 & $\mathrm{M}$ & 27 & 14 & $\begin{array}{l}\text { Exon } 3 \\
\text { splice Q40X }\end{array}$ & 2005 & 344 & 83 \\
\hline 8 & $\mathrm{~F}$ & 26 & 15 & P29S & 2911 & 1325 & 55 \\
\hline 9 & M & 22 & 18 & $\begin{array}{l}\text { Exon } 3 \\
\text { splice Q40X }\end{array}$ & 1631 & 349 & \begin{tabular}{|l|}
79 \\
\end{tabular} \\
\hline 10 & $\mathrm{~F}$ & 24 & 19 & C678+5G-T & 2033 & 53 & 97 \\
\hline 11 & $\mathrm{~F}$ & 23 & 21 & P29S & 1728 & 111 & 94 \\
\hline 12 & $\mathrm{~F}$ & 14 & 18 & $?(\operatorname{maps} 10 p)$ & 1102 & 10 & 99 \\
\hline 13 & $\mathrm{M}$ & 31 & 28 & Exon 3 splice & 2010 & 15 & 99.8 \\
\hline
\end{tabular}


Table 2.

Causes of exacerbations in plasma PA levels resulting in a> 50\% increase and exceeding a baseline level > 300 ìmol/L (10 x upper limit of normal).

\begin{tabular}{|l|l|}
\hline Cause of exacerbation & Number of episodes \\
\hline Weight loss & 12 \\
\hline Poor dietary compliance (patient report) & 10 \\
\hline Surgical/medical admission & 4 \\
\hline Infections & 3 \\
\hline Unknown & 4 \\
\hline
\end{tabular}




\section{Reference List}

1 Wierzbicki AS, Lloyd MD, Schofield CJ, et al. Refsum's disease: a peroxisomal disorder affecting phytanic acid alpha-oxidation. J Neurochem 2002 Mar;80(5):727-35.

2 Wierzbicki AS. Peroxisomal disorders affecting phytanic acid alpha-oxidation: a review. Biochem Soc Trans 2007 Nov;35(Pt 5):881-6.

3 Wanders RJ, Komen JC. Peroxisomes, Refsum's disease and the alpha- and omegaoxidation of phytanic acid. Biochem Soc Trans 2007 Nov;35(Pt 5):865-9.

4 Wanders RJ, Jansen GA, Skjeldal OH. Refsum disease, peroxisomes and phytanic acid oxidation: a review. J Neuropathol Exp Neurol 2001 Nov;60(11):1021-31.

5 Steinberg D, Mize CE, Herndon JH, Jr., et al. Phytanic acid in patients with Refsum's syndrome and response to dietary treatment. Arch Intern Med 1970 Jan;125(1):75-87.

6 Mukherji M, Schofield CJ, Wierzbicki AS, et al. The chemical biology of branched-chain lipid metabolism. Prog Lipid Res 2003 Sep;42(5):359-76.

7 Jansen GA, Waterham HR, Wanders RJ. Molecular basis of Refsum disease: sequence variations in phytanoyl-CoA hydroxylase (PHYH) and the PTS2 receptor (PEX7). Hum Mutat 2004 Mar;23(3):209-18.

8 Wierzbicki AS, Mayne PD, Lloyd MD, et al. Metabolism of phytanic acid and 3-methyladipic acid excretion in patients with adult Refsum disease. J Lipid Res 2003 Aug;44(8):1481-8.

9 Brown PJ, Mei G, Gibberd FB, et al. Diet and Refsum's disease. The determination of phytanic acid and phytol in certain foods and application of this knowledge to the choice of suitable convenience foods for patients with Refsum's disease. J Human Nutrition Dietetics 1993;6:295-305.

10 Coppack SW, Evans R, Gibberd FB, et al. Can patients with Refsum's disease safely eat green vegetables? Br Med J (Clin Res Ed) 1988 Mar 19;296(6625):828.

11 Westgard JO, Groth T. Design and evaluation of statistical control procedures: applications of a computer "quality control simulator" program. Clin Chem 1981 Sep;27(9):1536-45.

12 Fowler B, Burlina A, Kozich V, et al. Quality of analytical performance in inherited metabolic disorders: the role of ERNDIM. J Inherit Metab Dis 2008 Dec;31(6):680-9.

13 Wierzbicki AS, Mitchell J, Lambert-Hammill M, et al. Identification of genetic heterogeneity in Refsum's disease. Eur J Hum Genet 2000 Aug;8(8):649-51.

14 Wierzbicki AS, Sankaralingam A, Lumb PJ, et al. Transport of phytanic acid on lipoproteins in Refsum disease. J Inherit Metab Dis 1999 Feb;22(1):29-36. 
15 Gibberd FB, Billimoria JD, Page NG, et al. Heredopathia atactica polyneuritiformis (refsum's disease) treated by diet and plasma-exchange. Lancet 1979 Mar 17;1(8116):575-8.

16 Weinstein R. Phytanic acid storage disease (Refsum's disease): clinical characteristics, pathophysiology and the role of therapeutic apheresis in its management. J Clin Apheresis 1999;14(4):181-4.

17 Dry J, Pradalier A, Canny M. [Refsum's disease: 10 years of a diet low in phytanic acid and phytol]. Ann Med Interne (Paris) 1982;133(7):483-7.

18 Djupesland G, Flottorp G, Refsum S. Phytanic acid storage disease: hearing maintained after 15 years of dietary treatment. Neurology 1983 Feb;33(2):237-40.

19 Siegmund JB, Meier H, Hoppmann I, et al. Cascade filtration in Refsum's disease. Nephrol Dial Transplant 1995;10(1):117-9.

20 Hungerbuhler JP, Meier C, Rousselle L, et al. Refsum's disease: management by diet and plasmapheresis. Eur Neurol 1985;24(3):153-9.

21 Marcaud V, Defontaines B, Jung P, et al. [Refsum's disease: evolution 35 years after diagnosis]. Rev Neurol (Paris) 2002 Feb;158(2):225-9.

22 Eldjarn L, Try K, Stokke O, et al. Dietary effects on serum-phytanic-acid levels and on clinical manifestations in heredopathia atactica polyneuritiformis. Lancet 1966 Mar 26;1(7439):691-3.

23 Horn MA, van den Brink DM, Wanders RJ, et al. Phenotype of adult Refsum disease due to a defect in peroxin 7. Neurology 2007 Feb 27;68(9):698-700.

24 Lough AK. The phytanic acid content of the lipids of bovine tissues and milk. Lipids 1977 Jan;12(1):115-9.

25 Masters-Thomas A, Bailes J, Billimoria JD, et al. Heredopathia atactica polyneuritiformis (Refsum's disease): 1. Clinical features and dietary management. J Hum Nutr 1980 Aug;34(4):245-50.

26 Masters-Thomas A, Bailes J, Billimoria JD, et al. Heredopathia atactica polyneuritiformis (Refsum's disease): 2. Estimation of phytanic acid in foods. J Hum Nutr 1980 Aug;34(4):251-4.

27 van den Brink DM, van Miert JN, Dacremont G, et al. Identification of fatty aldehyde dehydrogenase in the breakdown of phytol to phytanic acid. Mol Genet Metab 2004 May;82(1):33-7.

28 Verhoeven NM, Jakobs C, Carney G, et al. Involvement of microsomal fatty aldehyde dehydrogenase in the alpha- oxidation of phytanic acid. FEBS Lett 1998 Jun $16 ; 429(3): 225-8$. 
29 Wierzbicki AS. Clinical significance of oxidation from phytol to phytanic acid in man. Mol Genet Metab 2004 Dec;83(4):347.

30 Gibberd FB, Billimoria JD, Goldman JM, et al. Heredopathia atactica polyneuritiformis: Refsum's disease. Acta Neurol Scand 1985 Jul;72(1):1-17.

31 Wierzbicki AS, Lloyd MD. Dr Brian Gibberd (1931-2006): a pioneering clinician in Refsum's disease. Biochem Soc Trans 2007 Nov;35(Pt 5):862-4. 